\title{
Foundations for Peacebuilding and Discursive Peacekeeping: Infusion and exclusion of conflict in Canadian public school curricula
}

\author{
Kathy Bickmore \\ Ontario Institute for Studies in Education, University of Toronto \\ Canada $^{\mathrm{i}}$
}

In Journal of Peace Education vol. 2 no. 2, Fall 2005

\begin{abstract}
Formal curriculum guidelines reflect prevailing understandings and political will, and help to shape the resources available for implemented curriculum. The understandings embodied in such public curriculum reinforce patterns of social violence and injustice, yet at the same time may provide diverse students with opportunities to develop commitment and critical citizenship capacity to handle social conflict. This paper examines the discourse about conflict, social diversity, and (in)justice in the mandated English Language Arts, Health, and Social Sciences curricula of three Canadian provinces. On one hand, all these curricula acknowledge the existence of bias and multiple viewpoints, and encode expectations for conflict management and critical inquiry skills, recognition of ethno-cultural diversity, and awareness of international interdependence and justice concerns. Thus a significant proportion of the knowledge, skill, and pedagogy called for by international peace and conflict educators is already included in these curricula. At the same time, these themes are primarily represented in abstract terms emphasizing 'Canadian' ideals, instead of examining many actual instances of social conflict. Is this anti-conflictual representation of social conflict a solid foundation for democratic peacebuilding, (and) or a gentle manner of peacekeeping through denial and indoctrination?
\end{abstract}

How can schools' curriculum be reasonably safe and inclusive for all students, and yet still prepare those young citizens to take part in the inevitable conflicts of society, including reconciliation and redress of injustice? Curriculum represents 'privileged discourse' that legitimates certain ways of thinking, and de-legitimates others (Giroux and McLaren, 1989, Apple, 1990). Curriculum and prevailing school practices often reinforce and reproduce overt violence (such as war-making and gender-based harassment) and structural violence (such as entrenched enmity and injustice).

However, they also simultaneously create some spaces (of varying sizes) for challenging and alleviating such violence.

This paper is drawn from a larger on-going study of peacekeeping (safety), peacemaking (dialogue and conflict resolution), and peacebuilding (equity and relationship-building) efforts in urban Canadian schools. It examines the ways conflict, social diversity, and (in)justice are handled in explicit official curriculum expectations (English Language Arts, Health, and Social Studies curricula, grade 1-10) in three Canadian provincial jurisdictions. What are the commonalities and variations among the discourses employed by these curriculum expectations, and how might these encourage or inhibit diverse students' development of agency and inclination for democratic engagement in handling social conflict? First, I open the complicated question of instilling values in peacebuilding education and then briefly introduce the Canadian school context and the curriculum analysis process used. Next, I describe the ways these curricula actually propose explicit values education for social harmony, expect individual critical thinking and conflict resolution skill-building, and offer a few specific instances of domestic and international social conflict as opportunities for citizenship learning. The paper concludes with questions raised by this case of curriculum-infused peacebuilding education. 


\section{Peacebuilding citizenship education}

Among diverse human beings in complex and shifting environments, conflict (meaning disagreements and struggles, not necessarily violence) is a constant. The modern nation state was consolidated through its monopoly on the use of force, yet virtually every state also sponsors public education as a (gentler?) means for forming citizens. Public school curricula reflect citizen negotiation, through governments, of the rules by which rights and differences are mediated and regulated (Stein, 2001). Thus 'peace' and peacebuilding education are built upon continual, imperfectly-democratic management of conflict.

'Peacebuilding' is defined by peace studies theorists as overcoming structural violence (exploitation, repression, marginalization) and cultural violence (subconscious beliefs or assumptions supporting violence (Galtung, 1996). Thus peacebuilding is essentially democratization, the development of processes for sustainably-nonviolent, inclusive, and equitable management of social conflict and human needs. By 'resolution,' I mean the process of dialogue and negotiating solutions to problems and disagreements, not to a presumed settlement or end point. There is neither need nor possibility for eliminating conflict, but it can be handled differently (Bickmore, 2003, Merelman, 1990).

Clearly values are inextricably embedded in all dimensions of conflict and conflict management, and therefore in conflict education. Values shape (and are shaped by) the knowledge, communication and interpretations that make up the substance of any conflict in its cultural context (e.g. Ross, 1993). Values are equally wrapped up in structures of social relationships, especially relationships across difference (who is 'we' and who 'they,' which identity groups are admired or marginalized) (e.g. Curle, 1971, Galtung, 1969). And, certainly, values are reflected and promoted by a society's mechanisms and decision rules for handling conflict (which parties are represented, whether the goal is blame/punishment or repair of harm, who is empowered to make binding decisions (e.g. Ury, 1999, Lederach, 1995). It is impossible to encode and communicate knowledge (to teach) without teaching values (e.g. Ellsworth, 1997, Freire, 1998). Beliefs are embedded in skills and substantive knowledge, and in school-based patterns of interaction. Certainly there is no guarantee that students will actually learn the citizenship values their teachers or curriculum writers intend; nevertheless any educational initiative embodies and (consciously or unconsciously) promotes particular values.

Many of the curriculum revisions proposed by peace and conflict educators emphasize the importance of teaching peaceable values and attitudes. Peacebuilding requires transforming cultural beliefs and narratives of enmity as well as repairing social-structural roots of violence (Tawil and Harley, 2004, Funk and Said, 2004). This emphasis on changing people's belief systems is especially pronounced in predominant peace education theory (e.g. Bar-Tal, 2002, Salomon and Nevo, 2002, Reardon, 1988, Harris and Morrison, 2003), and in conflict resolution education designed for children in school settings (e.g. Deutsch, 1993, Jones, 2004, UNICEF, 1997). For example, the UNESCO Declaration and Integrated Framework of Action on Education for Peace, Human Rights, and Democracy is particularly explicit about the goal of inculcating values:

The ultimate goal of education for peace, human rights and democracy is the development in every individual of a sense of universal values and types of behaviour on which a culture of peace is predicated. It is possible to identify even in different sociocultural contexts values that are likely to be universally recognized. Education must develop the ability to value freedom and the skills to meet its challenges. ... Awareness of personal responsibility must be linked to recognition of the value of civic commitment ... Education must teach citizens to respect the cultural heritage, protect the environment, 
and ... cultivate feelings of solidarity and equity...(UNESCO, 1995 Integrated

Framework, section 2.6-12)

Given the violent state of the world, presumably no peacebuilding citizenship educator pretends objectivity - we seek to reduce and transform violence and social exclusion. Yet the inculcation of values in 'public' schools can have decidedly undemocratic undertones.

"Indoctrination in the name of god, country, and goodness may simply be replaced by talk of the right way to make peace and build justice, ... and expand creative forms of dispute resolution" (Fisk, 2000 p. 181). What is the proper balance among 'teaching' values (presentation of 'truths' by nation state representatives), developing diverse citizens' capacities to disagree and to decide for themselves, and making young people aware of the ways they are constituted by (and co-create) the taken-for-granted discourses surrounding them in their communities and schools? This paper investigates the balance struck, and the particular discourses legitimated, in the public curricula affecting many Canadian students.

The (implicit) lived curriculum of pedagogy, school discipline and governance, resource use, and social inclusion and exclusion educates hand in hand with the (explicit) peace-, justice-, and conflict-related topics in the formal curriculum (Bickmore, 2004). Thoughtful naming provoked by dissonance (albeit embodying partial, socially-constructed understandings) is a necessary precondition for critical reflection and creative transformation (Engle and Ochoa, 1988, Freire, 1970, Festinger, 1964). Peacebuilding citizenship education involves identifying, interrogating, and reworking the implicit and explicit education about conflict that is already embedded in the lived and the official curriculum. Neither in stable Northern democracies such as Canada (Sears et al., 1999), nor even in revolutionary transition states in the South (Carnoy and Samoff, 1990), is it typical that mass public education would really emphasize a participative democratic peacebuilding ideal. Yet the contradictions and contestations within the system do offer spaces for critical transformative work (Ellsworth, 1997, Freire, 1998). Peacebuilding expectations in public curricula are a dynamic outcome of societal negotiation: Paradoxically, they both reflect some agreement in order to be implemented, yet also embody challenge to the violent and unjust status quo, in both their content and their discussion-based pedagogies (Bar-Tal, 2002).

This research is built on the assumption that public education (although it often reinforces structural/cultural violence and injustice) can help to strengthen peacebuilding capacity (Bush and Saltarelli, 2000, Davies, 2004). When it does, it does so by creating learning opportunities and resources that confront and interrogate substantive conflict patterns and issues (explicit curriculum), and as an arena for experiencing and practicing relatively equitable social relationships and conflict management processes in somewhat heterogeneous settings (implicit curriculum). This paper considers the value-laden conflict implications of explicit curriculum reflected in some official learning expectations in one country.

\section{Official curriculum in Canada}

This study examines official curriculum documents in three Canadian jurisdictions: Manitoba (MB, within a common western Canadian framework), Nova Scotia (NS, in a Atlantic Canada framework), and Ontario (ON, Canada's most populous province). English Language Arts, Health, and Social Studies in grades 1 to 10 (ages 6 to 16) were reviewed because they encompass the majority of compulsory courses offered before the minimum legal school-leaving age. All representations of conflict-, diversity-, and citizenship-related content and skill learning expectations, and teaching guidelines were extracted and coded according to emergent thematic categories. Many of the guidelines in these documents about active participation and critical thinking are in the introductory comments or in separate lists of skills. Since such general guidelines are often ignored 
by teachers relative to specific topical content expectations (Case and Wright, 1997), this analysis emphasizes the substantive content expectations.

English Language Arts curriculum may be a particularly important enabling structure, because in many public school systems, pushed by high-stakes literacy tests, a large portion of classroom time is allocated to this area. However, the most citizenship-relevant aspects of the curriculum may not be reflected in these officially-mandated standardized tests (Harber, 2002). The 'life skills' (including conflict resolution) strands of health curricula are generally attached to physical education: Classroom time for this area is often limited. Social Studies is the traditional home for explicit 'political' citizenship education, and for explicit nationalism: This curriculum area includes the widest range of conflict-related content (interpersonal through global). However, Social Studies also may suffer from limited classroom time: Many Canadian jurisdictions currently emphasize centralized mathematics and literacy testing.

Clearly there is no reason whatsoever to assume that any of these curricula are actually implemented as designed. At the same time, the discourse in such documents typically reflect a certain amount of consensus among the stakeholders (including teachers) who have had a hand in designing them - aspirations grounded in prevailing (subconscious) assumptions and understandings of what is worth knowing. These official documents reflect and reinforce legitimation of particular discursive understandings over others. Where conflicting and critical perspectives are included in curriculum guidelines, they at the least provide some security (grounds for defense of academic freedom) for those teachers who do choose to address contested terrain in their classrooms (Bickmore, 2002).

First I overview these curricula in general terms. Then I present and discuss a few curricular excerpts, in three emergent thematic groupings: harmony-building elements, individual skill-building elements, and explicitly 'political,' international, or conflictual elements. There were far more commonalities than differences in the three sets of curricula. Analysis revealed the following main themes (ordered from most to least emphasis):

\section{Harmony-building:}

1. Interpersonal contribution, responsibility, communication and cooperation

2. Appreciation of diverse heritages and viewpoints, multiculturalism, national unity

\section{Individual skill-building:}

3. Conflict resolution: managing disputes and avoiding violence

4. Critical reasoning and problem solving skills

Political, international and social conflict:

5. Citizen participation, governance \& (Canadian) ideals

6. Global interdependence: peace, human rights, and ecology

7. Social conflict issues (past or present conflicts or public controversies)

The three themes covered most frequently and consistently in these curricula - interpersonal communication and cooperation, appreciation for diversity, and conflict management/avoidanceseem primarily to promote values of non-confrontation and harmony. Even where the curricula attend to international interdependence and human rights concerns (theme 6, global interdependence), much of the emphasis is on inculcating values of caring for the other, similar to the representation of local and interpersonal diversity (theme 2). The vast majority of the conflict resolution content (theme 3 ) is applied to interpersonal disputes, and emphasizes polite (dominant culture) ways of restoring harmony. The underlying assumption seems to be that conflict can be destructive and should be avoided; indeed, most of the curriculum selections on these topics manage to avoid any explicit mention of conflict. Curricular elements that marginalize conflict and those with conflicting 
views can be seen as a form of anti-democratic peacekeeping or pacification - containment of disruption and thus protection of the status quo.

The critical reasoning, citizen participation and governance, global interdependence, and social conflict issues themes take up much less space in these curricula than the harmony themes just mentioned, but they are distinctly present, to different degrees in each province's guidelines. Even if taught in a politically 'neutral' manner (without questioning dominant assumptions or addressing controversies), if those skills and understandings were learned, they presumably could be applied to peacebuilding conflict management. However, international citizenship education research indicates that such conflict-avoidant curricula tend not to generate either much knowledge or interest among the majority of students. Explicit attention to controversial social issues could provide a stronger foundation for peacebuilding citizenship, by encouraging teachers and students to practice critical reasoning in applying democratic ideals to the complexities of real conflicts (Hahn, 1998, TorneyPurta et al., 2001). Such conflictual content was minimal and primarily limited in social studies, in the curricula reviewed, but it was present.

'Multiculturalism' is federal government policy in Canada: although provinces are not explicitly required to include this perspective in their curricula, all do so (Forbes, 1994, Derwing, 1992, Harper, 1997). In contrast, matters of gender or sexual identity and equity are mentioned far less than cultural diversities, in these curricula. As would be expected from prior scholarship cited earlier, to different degrees these curricula give little attention to matters of power imbalance/ inequity in present society, for example social class differences. Discrimination is predominantly presented as an abnormality or a past problem. There is remarkably little substantive international content (although there is somewhat more in the older grades 11 and 12, not analyzed for this paper): the 'expanding horizons' notion, in which younger children's worlds are assumed to be simple and local, still holds considerable sway. It is not surprising that potentially-controversial conflict issues are treated carefully (when they are addressed at all) in any publicly-disseminated political document. Nonetheless, it is interesting that various potential spaces for peacebuilding are opened in these curricula.

\section{Harmony-building (conflict-avoidant) curriculum elements}

Interpersonal communication and cooperation are heavily emphasized in these Canadian curricula for all three subjects. Teachers are pervasively encouraged to use student-centred teaching, groupwork, discussion, and experiential learning methods - although (or because) such pedagogies remain anything but pervasive in practice (Alexander, 2000, Sears et al., 1999). Even though conflict is an evident sub-text (the curriculum writers assume that people need to learn to get along), it is mentioned rarely. Strong attention in official curriculum rhetoric to communication and cooperation skills, tolerance and respect for differences, as well as critical thinking is nothing new, and is similar to official curricula in other countries (Collinge, 1993, Hicks, 1988). All the reviewed curricula emphasize respect for self and others and avoiding stereotypes. When this theme arises in Social Studies, it also points to the contributions of (essentialized) ethnocultural groups to Canada, the importance of national unity, and rights and freedom entitlements enshrined in the Canadian identity. A few curriculum passages include additional kinds of diversity (such as gender, ability, and economic status), usually in a long 'laundry list' of individual and social differences.

Conflict is the apparent sub-text and motivator of this attention to diversity, but it rarely breaks the surface into explicit text. The predominant approach is to advocate values of mutual acceptance and inclusive community. Many educators doubt whether such generally bland awareness-level attention to diversity would help to facilitate movement toward equity (Banks, 1988, McCauley, 2002). Attention to equity potentially could form a partial foundation for peacebuilding, if such curricula were put in practice with open, equitable dialogue and on-going cooperative contact among groups (Stephan, 1999, Tal-Or et al., 2002). 
These themes of interpersonal communication and cooperation and appreciating multicultural diversity are given a great deal of space, and handled in similar ways, in all three subject area curricula in all three provinces. For example:

In Manitoba ENGLISH LANGUAGE ARTS grade 8 (age 13-14 years), students “engage in dialogue to understand the feelings and viewpoints of others and contribute to group harmony." "ii Grade 4 (age 9-10): "identify similarities and differences between personal experiences and the experiences of people from various cultures portrayed in oral, literary, and media texts."

Manitoba PHYSICAL \& HEALTH Education strands throughout all grades include selfawareness/self-esteem/respect for others and social development/ appreciation of diversity. For example in grade 9 (age 14-15), "examine the effects of stereotyping based on a variety of factors (e.g. gender, age, race, roles, media influences, body type, sexual orientation, source of income...) and ways ... to promote acceptance of self and others."

Nova Scotia PHYSICAL \& HEALTH Education grade 7-9 (age 12-15) expects students to practice fair play, including "willingly choosing a variety of partners using a variety of criteria" and "valuing the participation of both male and female students."

Nova Scotia's SOCIAL STUDIES grade 9 course expects students to "demonstrate an understanding of the nature of culture, ethnic, and linguistic groups in Atlantic Canada," mentioning especially francophone, aboriginal, and Afro-Canadian groups.

Ontario SOCIAL STUDIES grade 1 (age 6-7) requires students to "demonstrate an understanding of rights and responsibilities in a way that shows respect for the rights and property of other people (e.g. sharing, cooperating)." In grade 5 (age 10-11), "demonstrate an understanding that for every right ... there is a responsibility." A typical approach to multicultural content, in grade 2 (age 7-8), asks students to "demonstrate an understanding that Canada is a country of many cultures [and] identify the significant features of various family cultures (e.g. food, dress, celebrations)." In grade 6, "identify the contributions of Aboriginal peoples to the political and social life of Canada (e.g. in music, art, politics, literature and science)."

The emphasis in this curriculum discourse is on social skills (communication, cooperation) and concepts (fair play, rights of others). Responsibility is emphasized more than rights: Thus overall, students are essentially expected to 'be good' — to cooperate and communicate without much sound nor fury - a very familiar notion of proper school behaviour. Such social codes may be taught positively and explicitly so that all might have relatively equitable opportunities to succeed (Delpit, 1995), but more likely are taught negatively by punishing those who either don't know or don't agree with those norms (Bickmore, 2004, Jull, 2000).

Unsurprisingly, these curricular passages place strong emphasis on Canadian identity (represented as ethnoculturally plural). The identities reinforced in these curricula respond in part to local histories: Nova Scotia, which has a long history of Black settlement, emphasizes AfroCanadian identities more than Ontario and Manitoba, whose African-heritage migrations came later than several waves of mixed European migration. While Ontario and especially Nova Scotia attend primarily to ethnic and linguistic differences without explicitly discussing discrimination or social conflict, Manitoba's curriculum attends to discrimination and social exclusion in relation to a wider range of social differences, including sexual orientation and social class. This prevailing 
'contributions' approach to social diversity appears to be aimed much more at harmony and conflict avoidance (peacekeeping) than at transforming conflictual social relationships (peacebuilding).

\section{Individual skill-building curriculum elements}

Awareness, skills, and practical processes for handling conflict (such as negotiation and peer mediation) are to be taught explicitly in Health ('life skills' strand) and Social Studies. Except indirectly through critical reasoning skills, the English Language Arts curricula reviewed do not explicitly teach peacemaking skills or concepts. This is a noticeable missed opportunity, since virtually every plot in children's literature, as well as much non-fiction writing, involves a conflict (and characters with viewpoints grounded in cultural settings) that could provide fuel for thoughtful discussion, role-play, or other conflict learning practice (Bickmore, 1999). Especially in Health, the curricula emphasize avoidance, settlement, and individual responsibility for preventing violence. Similar to the British national curriculum's ostensibly cross-curricular citizenship education requirement (Harber, 2002), the most explicit conflict resolution expectations tend to be clustered in health curricula (Personal, Social and Health Education in Britain), and to be heavily individualist and uncritical in character. The Social Studies curricula in Ontario and Manitoba call for a mix of individual, practical conflict management skills (similar to those in the Health curricula), plus some attention to social science concepts for understanding social-level conflicts.

Critical thinking skills - including information processing, decision making, interpreting multiple sources, recognizing bias - are described as essential in all three subject areas. In theory, these skills form part of a foundation for peacebuilding citizenship. However, except in Manitoba they are usually listed in overviews or in segregated 'skills' categories, disconnected from the topical content that many teachers understand as the 'real' curriculum requirements (Case and Wright, 1997). Especially in English Language Arts and Health, critical reasoning is mentioned primarily in generic overview statements, rather than embedded in specific knowledge-building expectations. Similarly, social justice and bias are mentioned in the abstract, but often (except in Ontario) not attached to particular instances or ramifications. Thus these curricula allow, but do not really require, much practice with substantive critique or conflict dialogue.

\section{Physical and Health Education}

Conflict resolution/ avoiding violence - MB General Learning Outcomes include safety (including violence and abuse prevention) and personal/ social management (including conflict resolution). For example grade 3 (age 7-8), "identify examples of real violence (e.g. schoolyard fights... bullying...) and fictional violence (e.g. cartoons, movies, TV wrestling...)" and "identify strategies (e.g. say no assertively, seek adult help... conflict resolution skills ... ) to avoid being bullied in different case scenarios." Grade 7 (age 1112), "describe scenarios that illustrate examples of physical, verbal, and emotionally abusive behaviours in different relationships." The HEALTH curriculum makes the conflict resolution strand even more explicit, for example grade 1, "demonstrate ways (e.g. using 'I' messages, compromising...) to resolve conflict in a peaceful manner with limited teacher input." Senior 1 (age 14-15), "apply conflict resolution strategies (i.e. mediation and negotiation) in different case scenarios for understanding different perspectives and points of view."

Critical reasoning - This MB framework also includes a problem-solving strand, such as in grade 3, "explore the steps in the decision-making/ problem-solving process (e.g. define topic or issue, explore alternatives, check and consider health knowledge and values, identify possible solutions, decide, evaluate...)." 
Conflict resolution/ avoiding violence - NS expects (grades 7-9) that a student "listens attentively, encourages others, disagrees in an agreeable way, criticizes ideas instead of the person..." and can "identify and practice strategies for dealing assertively with conflict" and (also in grade 5) for "managing anger."

Critical reasoning - This NS curriculum also recommends that students be provided opportunities to apply "critical, analytical and creative thinking to identify and solve problems, making decisions collaboratively." The foundation for all grades frames communication, problem solving, and the capacity to critically interpret information and different points of view as "essential graduation learnings."

Conflict resolution/ avoiding violence - The ON grade 1-8 over-all strand on "Personal Safety and Injury Prevention" attends to various types of violence, for example to "identify people and resources that can support someone experiencing harassment." ON HEALTH grade 9-10 includes a prominent section on conflict resolution, such as "understanding the triggers of conflict."

\section{Social Studies}

Conflict resolution/ avoiding violence - A MB general learning outcome, "Power and authority," includes "political structures and decision making, governance, justice, rules and laws, conflict and conflict resolution, and war and peace." Skills "for active democratic citizenship" are to pervade the curriculum, including "cooperation, conflict resolution, accepting differences, taking responsibility, negotiation, building consensus, collaborative decision-making, and learning to deal with dissent and disagreement." Specific learning outcomes include grade 5-8, "use a variety of strategies to resolve conflicts peacefully and fairly [such as] clarification, negotiation, compromise..." and grade 1, "Give examples of causes of interpersonal conflict and solutions to interpersonal conflict in the school and community."

Critical reasoning - "Skills for managing ideas and information" and "Critical and creative thinking skills" are to pervade this curriculum. For example grade 7, "compare differing viewpoints regarding global issues ... [and] analyze prejudice, racism, stereotyping, or other forms of bias in the media and other information sources."

Conflict resolution/ avoiding violence - The ON "Canada and World Connections" strand (all grades) identifies specific examples of divergent viewpoints, conflict and conflict resolution. The HISTORY grade 7 "Conflict and Change" unit emphasizes interpersonal and intergroup conflict and conflict management. For example, "demonstrate an understanding of the rivalries between the French and English in North America and Europe (e.g. between the Hudson's Bay Company and the North West Company, [and] between Aboriginal allies..." [and] "demonstrate an understanding of the nature of change and conflict, identify types of conflict (e.g. war, rebellion, strike, protest) and present strategies for conflict resolution." CIVICS grade10 expects students to "demonstrate an ability to anticipate conflicting civic purposes, overcome personal bias, and suspend judgement in dealing with issues of civic concern" and to "analyze approaches to decision-making and conflict resolution that affect their own lives." 
Critical reasoning - In the ON CANADIAN/WORLD STUDIES grade 9 "Geography of Canada" course, students are to "analyse the factors that cause change, and forecast the effects of change in the relationships between the earth's natural and human systems ... [and to carry out] problem solving and planning."

\section{English Language Arts}

Critical reasoning - The MB Senior 1-3 (age 14-17) overview says: "Texts provide opportunities for thinking and talking about a wide range of topics and ideas, including those relating to society, ethics, and the meaning and significance of experiences... [and students should] become more conscious, discerning, critical, and appreciative readers of visual media and more effective creators of visual products. Students need to recognize that what a camera captures is a construction of reality, not reality itself."

Critical reasoning - The NS grade 4-6 overview emphasizes "critical literacy," including helping students to recognize "how text constructs one's understanding and worldview of race, gender, social class, age, ethnicity, and ability" and giving students "the means to bring about the kind of social justice that a democracy seeks to create."

Critical reasoning - The ON grade 1-8 guidelines invite students to participate in "brainstorming, discussing strategies for problem solving, debating issues, presenting and defending ideas, and offering critiques of the ideas of others" and "identifying values and issues, detecting bias, detecting implied as well as explicit meanings." An ON English grade 9 unit, "Literature Studies and Reading," expects students to "use specific evidence from a text to support opinions and judgements (e.g. role-play a court trial of the antagonist in a story, formally debate issues raised in a text, use direct quotations in an answer to a homework question" [and] "explain how readers' different backgrounds might influence the way they understand and interpret a text." A "Media Studies" unit expects students to "adapt an idea or theme from a work of literature... (e.g., recast a conflict from a novel as a debate on a television or radio talk show...)."

One could certainly argue that critical reasoning and conflict resolution skills are a necessary (though not sufficient) prerequisite for conflict resolution and peacebuilding. The Health curricula in all three provinces emphasize individual strategies for avoidance and dispute settlement, rather than comprehension or critique of the sources of destructive conflict and violence in schools, communities, and the world. The implication (most explicit in the Manitoba Health curriculum) that students should use interpersonal skills to avoid bullying and abusive situations is problematic: It places heavy responsibility on the individual student who may be a victim.

In Health, the implication is that conflict is a negative, whereas in Social Studies (except in Nova Scotia), there is some attention to confrontation of conflict (such as strikes, rebellions, protests) that could result in positive social change. In Ontario, the explicit requirement to teach conflict resolution skills and processes in Health is a relatively recent change in the official curriculum, whereas the topic has deeper roots in Social Studies. These Health curricula disconnect conflict from its social meanings, social structural causes, and potential positive outcomes, and seem (at least by default) to legitimate the use of force by the powerful while de-legitimating disruption by the less powerful. Critical thinking is primarily presented as an attitude or a technical skill, disconnected from any particular substantive topic. The individualistic, skill-building approach of these curricula, especially in combination with the harmony elements of the same curricula discussed earlier, is consistent with prevailing theory and guidelines in conflict resolution education (e.g. Carruthers et al., 
1996, Bodine and Crawford, 1998, Johnson and Johnson, 1996, Jones, 2004). This uncritical liberalrational paradigm may help to explain the extremely rapid adoption of conflict resolution education goals in mainstream curricula.

\section{'Political,' international, and social conflict curriculum elements}

Explicit citizenship education is unique to Social Studies in the curricula reviewed. Unsurprisingly, these curricula exhibit a visible nationalism: Canadian identity is presented in a very positive light, and associated with values/ideals of equality, rights, and participation. Where the curricula do occasionally problematize intersections among governance or national identity and diversity, injustice, and social conflict, this offers teachers and students opportunities to practice constructive confrontation of the conflict inherent to democracy.

The concepts of ecological and human relationships (global interdependence) emerge primarily in Social Studies, but occur slightly in other subject areas in Ontario and Nova Scotia. There is relatively little international content even mentioned in these grade 1-10 curricula. Similar to the interpersonally-oriented theme of appreciating diversity, international diversity and human rights are presented primarily as uncontested abstract ideals. The discourse of global interdependence masks the pitfalls of marginalization and 'dependence' for the less powerful.

Controversy is rarely encouraged in these curricula, but it is not totally ignored (especially in Social Studies). The English Language Arts curricula make essentially no specific mention of specific social conflicts, although (depending on what literature students read, and on classroom climates) there are a number of potential spaces for such discussions. Health education similarly avoids nearly all mention of social controversy, except for mention in the Nova Scotia curriculum introduction that the use of certain curricular resources might be contested, yet worth doing. Even in Social Studies, to different degrees in each province, discrimination against specific out-groups is framed primarily as past, as if such problems were largely solved.

These themes highlight a crucial challenge in international citizenship/ peacebuilding education: Ideals of constructive interdependence, tolerance and human rights only acquire meaning in relation to the violations, traumas, and uncertainties inherent in deep social conflict (Avery et al., 1997). These public school curricula interpret international peace and social cohesion education as requiring fly-by grand intentions rather than close encounters with uncomfortable knowledge. There is no reason to assume that, at this level of abstraction, exhorting students to respect human and environmental diversity and interdependence would have appreciable effect. Yet scattered unevenly across these curricula are a few potentially interesting opportunities to engage in, rather than merely hope at a distance for, creating just peaceful relations.

\section{Physical/ Health Education and English Language Arts}

Global interdependence - The NS PHYSICAL and HEALTH EDUCATION overview for all grades includes, as key principles, citizenship and nurturing "self-reflection and consciousness that preserve human rights and the development of supportive and sustainable environments for all citizens." Specific expectations include "assess cultural, economic, and environmental interdependence in local and global contexts."

Global interdependence - An ON ENGLISH LANGUAGE ARTS grade1-8 guiding principle is to equip students with the "knowledge and skill that will help them compete in a global economy and allow them to lead lives of integrity and satisfaction, both as citizens and individuals."

\section{Social Studies}


Canadian citizenship/ideals - The MB Framework of Outcomes grade K-8 describes "citizenship as a core concept," including ways individuals and groups influence the making of laws, redress past and present injustices (e.g. resource extraction from Aboriginal communities), and handle conflicts (e.g. global disparities in wealth \& human rights). This "active democratic citizenship in Canada" approach insists upon recognition of Canada's "bilingual and multicultural nature... respect for human rights and democratic ideals and principles, ability to work through conflicts and contradictions that can arise among citizens, commitment to freedom, equality, and social justice..." For the "Power and authority" general learning outcome, in grade 5, students are to examine "the authorization of some individual or group within a society to make binding decisions... [which may] vary from one society to another." Grade 9 Canadian Studies claims, "conflict between increasing needs and wants and limited resources is a fundamental economic problem which necessitates a decision-making system. In Canada, the political system is... marked by federal-provincial tensions."

Global interdependence - Two MB general learning outcomes include "identity, culture, and community" and "global interdependence." Specific outcomes in the grade 7 "Spaceship Earth" course include: "give examples of global cooperation to solve conflicts or disasters," "identify various international organizations and describe their role in protecting or enhancing global quality of life," and "identify universal human rights and explain their importance" (101). Grade 8, "People through the Ages," includes "how the First World, Second World, and Third World developed and how life compares and contrasts in these "worlds' ... and how may the Third World be affected by the First World." Grade 6, "Life in Canada's Past" includes "what impact did the arrival of [various waves of British] settlers have on the lives of French and Native people already living in the area." Grade 9 Canadian Studies examines "what role does Canada play in keeping peace in the world?"

Social conflict - Specific skill outcomes in this MB curriculum include (grade 5-8), "recognize bias [and] discrimination and propose solutions." A grade 6 unit on Western Canada includes "the relocation of Native People onto reserves," and "how is life in a contemporary reserve similar to and different from life on a reserve in the past." The grade 7 curriculum, "Spaceship Earth," includes "what different conflicts may arise as a result of interaction of various cultural groups? What could help to prevent or counteract these conflicts?" The curriculum's 'core concepts' highlight "Canadian citizenship for the future" including "redressing past and present injustices" and "eliminating inequalities," "citizenship in the global context" including "help reduce the disparities and human rights violations that have become a common means of addressing internal and international disputes," and "environmental citizenship."

Canadian citizenship/ideals - The NS grade 1-12 foundation emphasizes democratic values and principles such as equality, dignity, justice, freedom, civil rights and responsibilities, and universal human rights. Curriculum outcomes emphasize that students should "take age-appropriate actions to demonstrate their responsibilities as citizens." Two of six 'key-stage curriculum outcomes' are 'citizenship' and 'power and governance,' in which students identify, analyze, and compare relations of power and authority, understand how the Canadian legal system "establishes order and manages conflict," and understand "how groups, institutions, and media influence people and society." The grade 9 course, "Atlantic Canada in the Global Community," expects 
students to "explain how Atlantic Canadians shape political culture by exercising power and influencing political decisions."

Global interdependence - The introduction emphasizes student-centred teaching focused on "stimulating ideas, social issues, and themes," encouraging students "to examine issues, respond critically and creatively, and make informed decisions as individuals and as citizens of Canada and of an increasingly interdependent world." Additional key outcomes are 'culture and diversity' and 'interdependence,' including analyzing human rights and other global issues (unnamed) and planning and evaluating actions for peace and sustainability. In grade 9, students "explain and analyse how Atlantic Canadians are members of the global community [and] need to become contributing members of the global community."

Social conflict - The introduction encourages use of potentially-controversial resources - "given the diverse nature and maturity of students, it is important to confront important issues and bring them into the open for discussion"- and provides strategies for teachers to defend their use of such resources if community members raise objections. Curriculum outcomes assert that social and cultural groups have different perspectives on social issues, and mention discrimination. In grade 9, students are to "demonstrate an understanding of the issues and events surrounding cross-cultural understanding in the local, regional, and global levels" including prejudice, discrimination, social injustice, ethnocentrism, multiculturalism, and anti-racism.

Canadian citizenship/ideals - The ON "Canada and World Connections" grade 5 unit on "Aspects of the Government in Canada," expects students to understand how federal and provincial governments ensure unity through governance mechanisms. A Civics grade 10 overall expectation is that students "demonstrate an understanding of the reasons for democratic decision making [and] compare contrasting views of what it means to be a citizen." A main course strand is "Active Citizenship:" students are to "demonstrate an understanding of a citizen's role in responding to non-democratic organizations (e.g. supremacist and racist organizations) [and to] compare and evaluate the impact of various non-violent citizen participation." The grade 10 "History of Canada" course specifies that "study of these social structures considers the relationships among ordinary people in society, gender roles ... the interaction between majorities and minorities..."

Global interdependence - A Canada and World Connections grade 4 unit on the "Provinces and Territories of Canada" asks students to "identify how different regions are interdependent." A Heritage and Citizenship grade 6 unit, "Aboriginal Peoples and European Explorers," requires students to "identify some of the consequences of Aboriginal and European interactions (e.g. economic impact of the fur trade on Aboriginal peoples, transmission of European diseases to Aboriginal peoples)." Geography grades 7-8 describes interdependent relationships of trade, and views protecting the environment as a responsibility of citizenship. The grade 9 course, Geography of Canada, includes a "Global Connections" strand, "Since the world's economies are becoming increasingly interconnected, and the flow of people, products, money, and ideas around the world is accelerating...." Another grade 10 course, Canadian History in the 20th Century, has students "explain the significance of Canada's contribution to the forces of globalization and the United Nations (e.g. Universal Declaration of Human Rights, treaty on land mines, children's rights)." 
Social conflict - In grade 6 "Heritage and Citizenship," students "identify current concerns of Aboriginal peoples (e.g. self-government, land claims)." In History grade 7, a "Conflict and Change" unit focuses on historical instances of conflict such as the rebellions of 1837 in Upper and Lower Canada. Students are to "analyze and describe conflicting points of view about an historical event (e.g. the expulsion of the Acadians), giving examples of fact and opinion [and to] describe the impact of the Treaty of Paris and the Quebec Act from both the English and the French points of view." In grade 8, students are to understand "the growth and development of the West from the points of view of the Canadian government, Aboriginal peoples, Metis, and new immigrants," also "major developments that affected the working conditions of Canadian workers (e.g. development of unions, Winnipeg General Strike)," and to "identify major developments (e.g. the suffrage movement) and personalities ... in the women's rights movement, and demonstrate an understanding of the changing role of women in Canadian society." In Canadian and World Studies grade 10, students are to "explain how and why social support programs (e.g. old age pensions, unemployment insurance, medicare) were designed, and assess their effectiveness in meeting the needs of various segments of society." Students also must "explain how and why the Canadian government restricted certain rights and freedoms in wartime, and "describe the impact... of these restrictions on the general population and on various groups within the Canadian population."

The above curriculum expectations, especially in Ontario and Manitoba, are in many ways in line with the recommendations of peace education scholars, in that they emphasize the responsibility of citizens to recognize some fundamental sources of social conflict and injustice, and to participate in nonviolent citizen action in response to such problems. However, specific international content is relatively scarce (in the curricula for grades 10 and younger, reviewed here). Interconnection and interdependence are mentioned a great deal, but power imbalance, dependence, or specific conflicts are mentioned very little. The language of global perspective and human rights has been adopted, but there is no requirement to allocate time to examine specific international people, places, or problems.

Only the above small, least-frequent excerpts from the reviewed curricula (even there, primarily in Ontario and Manitoba and in Social Studies) begin really to address the foundations of conflict, in specific enough terms to potentially provoke investigation and expression of challenging ideas. Official citizenship education curricula reflect the intentions of the state (in this case, provincial governments and their major stakeholders) in relation to national identity and social cohesion (Mátrai, 2002). The foregoing examination of curriculum discourse suggests that these Canadian provincial governments (despite the democratic language with which the documents are introduced) are at best ambivalently committed to active, critical citizen agency in relation to the conflicts of our times.

Johan Galtung distinguishes between basic symptoms of harm such as poverty and war, which he calls problems, and the underlying structures that cause those problems, which he calls conflict formations:

We cannot continue teaching our pupils and students about 'problems' in general; we have to be more honest and place these problems in their political setting - and the conflict formations give a good basis for doing so. Of course, this brings us into 'politics,' and to believe that we can have anything like peace education without touching politics is not only naive, but also in itself a very political point of view, and a way of manipulating young people so as to make them insensitive to the reality of the world around them (in Curle et al., 1974 p.83-84). 
While the curricula reviewed above do (at least obliquely) address some social problem symptoms such as bias, stereotyping, war and human rights violations, they very rarely require students and students to address either specific instances or the underlying foundations of such problems. A curriculum that does not trouble students' assumptions about the status quo and their place in it is thereby teaching (dominant) values, just as certainly as would be a more self-consciously 'political' curriculum. Implicit denial of social conflict foundations shuts down potential spaces for conscientization and critique. Given that most citizens' (and teachers') international and explicit political knowledge is minimal, a lack of specific content examples in the curriculum expectations virtually guarantees that these specific 'conflict formations' will usually not be addressed.

\section{Conclusion}

This paper has examined the potential spaces for democratic peacebuilding education that are embodied (and absent) in some Canadian provinces' official curriculum guidelines. There are plenty of potential and partial foundations for peacebuilding in these curricula's rhetorical attention to social harmony values such as interpersonal communication, cooperation, and appreciation of diversity, to individual skills such as conflict resolution and critical reasoning, and to citizen engagement and interdependence at global and local levels. Thus these curricula do, in many ways, fulfill many of the goals outlined in influential international peace and conflict education theories and guidelines.

However, there are very few instances in these curricula of direct attention to the roots, characteristics, and contrasting viewpoints of specific social conflicts, especially gendered social relations or social-structural, transnational problems. To different degrees in the various subject areas and jurisdictions, these curricula seem to contribute more to discursive peacekeeping -implicit social control through denial and inculcating unproblematized values - than to democratic peacebuilding. To contribute to democratic peacebuilding, explicit curriculum would have to delve into the unsafe but 'real' world of social and political conflicts that defy simple negotiated settlement, including the roots and human costs of current local and global injustices. Where these curricula still appear inadequate to the task of peacebuilding, peace education theorists need to clarify more explicitly what is still missing - especially, the roles of specific equity challenges, substantive content, and student participation in the clarification and acquisition of values.

At the same time, unresolved social conflicts, and the expectation that diverse students are becoming citizens with agency in relation to those conflicts, are evident sub-texts throughout these curricula - occasionally even in explicit 'required learning.' Thus these curricula do provide a rationale, a motivational nudge, and a protective safety net for teachers who do choose to address the unsafe topics and perspectives necessary for peacebuilding citizenship education. The next challenge, therefore, is to narrow the distance between intended and experienced curriculum, by facilitating critically reflective implementation in diverse settings.

References

Alexander, R. (2000) Culture and Pedagogy: International Comparisons in Primary Education, Blackwell, Malden, MA \& Oxford, UK.

Apple, M. W. (1990) Ideology and Curriculum, Routledge, New York.

Avery, P., Sullivan, J. and Wood, S. (1997) Theory Into Practice, 36, 32-38.

Banks, J. (1988) Multicultural Leader, 1, 1-3.

Bar-Tal, D. (2002) In Peace Education: The Concept, Principles, and Practices around the World(Eds, Salomon, G. and Nevo, B.) Lawrence Erlbaum Associates, Mahwah, NJ, pp. 27-36. 
Bickmore, K. (1999) In How Children Understand War and Peace(Eds, Raviv, A., Oppenheimer, L. and BarTal, D.) Jossey-Bass, San Francisco, pp. 233-259.

Bickmore, K. (2002) Theory and Research in Social Education, 198-216.

Bickmore, K. (2003) In Handbook of Conflict Management(Eds, Pammer, W. and Killian, J.) Marcel-Dekker Publishers, pp. 3-32.

Bickmore, K. (2004) Theory and Research in Social Education, 32, 75-97.

Bodine, R. J. and Crawford, D. J. (1998) The Handbook of Conflict Resolution Education: A Guide to Building Quality Schools, Jossey-Bass with National Institute for Dispute Resolution, San Francisco.

Bush, K. and Saltarelli, D. (2000) UNICEF Innocenti Research Centre, Florence, IT.

Carnoy, M. and Samoff, J. (1990) In Education and Social Transition in the Third World(Eds, Carnoy, M. and Samoff, J.) Princeton University Press, Princeton, pp. 361-380.

Carruthers, W., Caruthers, B., Day-Vines, N., Bostick, D. and Watson, D. (1996) The School Counselor, 43, 345-373.

Case, R. and Wright, I. (1997) In The Canadian Anthology of Social Studies: Issues and Strategies for Teachers(Eds, Case, R. and Clark, P.) Simon Fraser University, Burnaby, BC, pp. 179 - 193.

Collinge, J. (1993) In Peace Education Miniprints No. 52Malmo, Sweden.

Curle, A. (1971) Making Peace, Tavistock Publications, London.

Curle, A., Freire, P. and Galtung, J. (1974) In Education for Peace: Reflection and Action(Ed, Haavelsrud, M.) University of Keele, Keele, UK, pp. 64 - 97.

Davies, L. (2004) Education and Conflict: Complexity and Chaos, Routledge/Falmer, London.

Delpit, L. (1995) Other people's children: Cultural conflict in the classroom, New Press, New York.

Derwing, T. (1992) In Socio-political Aspects of ESL(Eds, Burnaby, B. and Cumming, A.) OISE Press, Toronto, pp. 193-202.

Deutsch, M. (1993) American Psychologist, 48, 510-517.

Ellsworth, E. (1997) Teaching Positions: Difference, Pedagogy, and the Power of Address, Teachers College Press, New York.

Engle, S. and Ochoa, A. (1988) Education for Democratic Citizenship, Teachers College Press, New Yorl.

Festinger, L. (1964) Conflict, Decision, and Dissonance, Stanford University Press, Stanford, CA.

Fisk, L. (2000) In Patterns f conflict, paths to peace(Eds, Fisk, L. and Schellenberg, J.) Broadview Press, Peterborough, ON, pp. 159-193.

Forbes, H. D. (1994) In Nationalism, Ethnic Conflict and Democracy(Eds, Diamond, L. and Plattner, M.) Johns Hopkins University Press, Baltimore, pp. 86-101.

Freire, P. (1970) Pedagogy of the Oppressed, Seabury Press, New York.

Freire, P. (1998) Pedagogy of Freedom: Ethics, Democracy, and Civic Courage, Rowman \& Littlefield, Lanham, MD.

Funk, N. and Said, A. A. (2004) International Journal of Peace Studies, 9, 1-28.

Galtung, J. (1969) Journal of Peace Research, 167-192.

Galtung, J. (1996) Peace By Peaceful Means: Peace and Conflict, Development, \& Civilization, Sage Publications \& International Peace Research Assn, London.

Giroux, H. and McLaren, P. (Eds.) (1989) Critical Pedagogy, the State, and Cultural Struggle, SUNY Press, Albany.

Hahn, C. (1998) Becoming Political: Comparative Perspectives on Citizenship Education, State University of New York Press, Albany.

Harber, C. (2002) In Learning Democracy and Citizenship: International Experiences(Eds, Schweisfurth, M., Davies, L. and Harber, C.) Symposium Books, Oxford, UK, pp. 225 - 237.

Harper, H. (1997) Canadian Journal of Education, 22, 192-206.

Harris, I. M. and Morrison, M. L. (2003) Peace Education (2nd edition), McFarland, Jefferson, NC:

Hicks, D. (1988) In Children and Controversial Issues(Eds, Carrington, B. and Troyna, B.) Falmer Press, London, UK, pp. 172-188.

Johnson, D. and Johnson, R. (1996) Review of Educational Research, 66, 459-506.

Jones, T. (2004) Conflict Resolution Quarterly, 22, 233-267.

Jull, S. (2000).

Lederach, J. P. (1995) Preparing for peace: Conflict transformation across cultures, Syracuse University Press, Syracuse. 
Mátrai, Z. (2002) In New Paradigms and Recurring Paradoxes in Education for Citizenship: An International Comparison(Eds, Steiner-Khamsi, G., Torney-Purta, J. and Schwille, J.) JAI/ Elsevier Science, Amsterdam, pp. 85-104.

McCauley, C. (2002) In Peace Education: The concept, principles, and practices around the world(Eds, Salomon, G. and Nevo, B.) Lawrence Erlbaum Associates, Mahwah, NJ, pp. 247-258.

Merelman, R. (1990) In Political socialization, citizenship education, and democracy(Ed, Ichilov, O.) Teachers College Press, New York, pp. 47-65.

Reardon, B. (1988) Comprehensive Peace Education: Educating for global responsibility, Teachers College Press, New York.

Ross, M. (1993) The Management of Conflict, Yale University Press, New Haven.

Salomon, G. and Nevo, B. (Eds.) (2002) Peace Education: The Concept, Principles, \& Practices around the World, Lawrence Erlbaum Associates, Mahwah, NJ.

Sears, A., Clarke, G. and Hughes, A. (1999) In Civic Education Across Countries: Twenty-Four National Case Studies from the IEA Civic Education Project(Ed, Torney-Purta, J., J. Schwille, \& J. Amadeo), pp. 111-135.

Stein, J. (2001) The Cult of Efficiency, Anansi Press, Toronto.

Stephan, W. (1999) Reducing Prejudice and Stereotyping in Schools, Teachers College Press, New York.

Tal-Or, N., Boninger, D. and Gleicher, F. (2002) In Peace Education: The Concept, Principles, and Practices around the World(Eds, Salomon, G. and Nevo, B.) Lawrence Earlbaum Associates, Mahwah, NJ, pp. 89-107.

Tawil, S. and Harley, A. (Eds.) (2004) Education, Conflict \& Social Cohesion, UNESCO/ International Bureau of Education, Geneva.

Torney-Purta, J., Lehmann, R., Oswald, H. and Schultz, W. (2001) Citizenship and Education in 28 Countries, I.E.A. Secretariat (International Assn. for the Evaluation of Educational Achievement), Amsterdam.

UNESCO (1995) UNESCO (United Nations Educational, Scientific and Cultural Organization), Paris.

UNICEF (1997) Education for peace and conflict resolution. A training and curriculum support manual, UNICEF Canada, Toronto.

Ury, W. (1999) The third side: Why we fight and how we can stop, Penguin, New York.

\section{Curriculum documents cited}

Manitoba ENGLISH LANGUAGE ARTS all grades (1996)

Manitoba ENGLISH LANGUAGE ARTS Senior 1-3 (1998)

Manitoba PHYSICAL/HEALTH EDUCATION Framework for all grades (2000)

Manitoba HEALTH all grades (2000)

Manitoba SOCIAL STUDIES Framework of Outcomes grade K-8 (2003)

Nova Scotia ENGLISH LANGUAGE ARTS grade 4-6 (1998)

Nova Scotia PHYSICAL/HEALTH EDUCATION Foundation grade 1-12 (1998)

Nova Scotia PHYSICAL \& HEALTH Education for all grades (1999)

Nova Scotia PHYSICAL \& HEALTH EDUCATION grades 7-9 (1999)

Nova Scotia SOCIAL STUDIES Foundations grade 1-12 (1998)

Nova Scotia SOCIAL STUDIES grade 9 course, "Atlantic Canada in the Global Community" (1998)

Ontario SOCIAL STUDIES grade 1-6 (1998)

Ontario HISTORY grade 7-8 (1998)

Ontario GEOGRAPHY grade 7-8 (1998)

Ontario CIVICS grade10 (1998)

Ontario CANADIAN/WORLD STUDIES grade 9 and 10 course (1999)

Ontario PHYSICAL/HEALTH EDUCATION grade 1-8 (1998)

Ontario ENGLISH LANGUAGE ARTS 1-8 (1997)

Ontario LANGUAGE grade 1-8 (1997)

Ontario ENGLISH grade 9-10 (1999) 


\footnotetext{
${ }^{\mathrm{i}}$ Earlier versions of this paper were presented at the British Association for International and Comparative Education (September 2004) and the American Education al Research Association (April 2005).

ii Italics added periodically in the curriculum excerpts highlight particular elements to be discussed in the accompanying text.
}

\begin{abstract}
About the author: Kathy Bickmore (Ph.D. Stanford University 1991) is Associate Professor and Coordinator of the graduate program in Curriculum at OISE, University of Toronto, Canada (OISE/UT, 252 Bloor Street West, \#10-170 Toronto, Ontario M5S 1V6 Canada, kbickmore@oise.utoronto.ca). She teaches (graduate and teacher education) and conducts research about education for constructive conflict, peacebuilding, conflict resolution, equity, and citizenship/ democratization in public school contexts.
\end{abstract}

